\title{
Fostering evidence-based practice in community-based rehabilitation: strategies for implementation
}

\author{
Helen Buchanan, BSc O T (UCT), MSc O T (UCT), PhD OT (UCT) \\ Senior Lecturer, Division of Occupational Therapy, Department of Health and Rehabilitation Sciences, University of Cape Town
}

\section{Theresa Lorenzo, BSc OT (Wits), HDEdAd (Wits), MSc (CommDisStud) (London) PhD (UCT)}

Associate Professor, Department of Health and Rehabilitation Sciences, University of Cape Town.

\section{Mary Law, PhD, FCAOT}

Professor Emeritus, School of Rehabilitation Science and CanChild Centre for Childhood Disability Research, McMaster University, Canada

Occupational therapists around the world are taking up the challenge to implement an evidence-based practice approach to the development of occupational therapy services. The emphasis in applying evidence-based practice within occupational therapy has been strongly biomedical in focus. In South Africa, many occupational therapists work in communities where their work is largely communitybased rehabilitation. With no examples of how evidence-based practice can be applied in such settings, therapists have struggled with how it may be used to inform their practice. This paper explores the concepts of evidence-based practice and community-based rehabilitation, and illustrates how evidence-based practice can be applied within community-based rehabilitation. Examples are provided to show how evidence-based practice can realistically be applied in community-based rehabilitation programmes with the intention of empowering therapists to begin using evidence as a basis for their practice. It further explores how evidence-based practice can be used by occupational therapists to inform decision-making related to the development of community-based rehabilitation programmes and services.

Keywords: evidence-based practice, community-based rehabilitation, occupational therapy, practice-based evidence

\section{INTRODUCTION}

Occupational therapists around the world are taking up the challenge of implementing an evidence-based practice (EBP) approach to the development of occupational therapy services'. EBP has been largely applied to practice that is biomedically orientated whereas in South Africa, many occupational therapists work in programmes with a development and social inclusion focus in which their work is largely community-based. There is a dearth of literature about EBP in community-based rehabilitation (CBR) which weakens the expansion of inclusive service delivery. Furthermore, EBP would provide stronger support for policy implementation to ensure inclusive service delivery for persons with disabilities. With no examples of how EBP can be applied in CBR programmes, therapists have struggled with how it may be used to inform their practice.

With the ratification of the United Nations Convention on the Rights of People with Disabilities (UNCRPD) $)^{2}$ by many countries, the implementation of the new CBR Guidelines that were launched by the World Health Organisation (WHO) in $2010^{3}$, provide a practical framework for achieving the rights of persons with disability. CBR is seen as a complex form of change because of the intersectoral co-ordination and collaboration required to get systems to work efficiently and effectively across different government departments, public and private sectors, and nongovernmental organisations (NGOs). The nature of this work requires the development of a work force with a new skill set to enable transdisciplinary work. The need for evidence of the effectiveness and efficiency of CBR as a community development strategy to equalise opportunities for persons with disabilities has critical relevance to ensure inclusive service delivery particularly in the light of the current initiatives towards the Re-engineering of Primary Health Care by the National Department of Health. The routine use of indicators and outcome measures is long overdue to create the evidence needed for CBR. This paper explores how EBP can be applied within CBR and provides examples of how it could be used to inform decision-making.

\section{CBR - a strategy for inclusive health, education, livelihood and community living}

CBR has been practised in a range of different contexts globally since the 1980s. More recently, CBR has been recognised as a general community development strategy for equalising opportunities of persons with disabilities, through rehabilitation, poverty reduction and social inclusion together with their families and in their communities ${ }^{3}$. CBR embraces an intersectoral approach involving health, social development, labour, housing and education as primary sectors. Transport and communication sectors should also be seen as essential for equalising opportunities. CBR programmes would therefore be well placed under local government and within the district health system for implementation and service delivery. National and provincial governments in South Africa have however, been slow to commit themselves to funding CBR programmes with the exception of three provinces. One of the main reasons is that evidence has not been provided to show the effectiveness of CBR in meeting the needs of disabled people.

The UNCRPD recognises the fluidity required in defining disability. The preamble states that "Persons with disabilities include those who have long-term physical, mental, intellectual or sensory impairments which, in interaction with various barriers, may hinder their full and effective participation in society on an equal basis with 
others" 2: I. Persons with disabilities need to have equal opportunities to belong and participate in everyday activities, and to make a contribution to their families, schools, workplaces and communities. The concept of equal opportunity has been defined as the process through which the various systems of society and the environment, such as services, activities, information and documentation, are made available to all $^{4}$. Participation and universal design are central to any intervention aimed at promoting equal opportunities. Disabled People's Organisations (DPOs), health professionals and development practitioners recognise poverty and disability as two of the greatest challenges in promoting and protecting the rights of marginalised or vulnerable groups, including people with disabilities. To ensure health and well-being for all, occupational therapists and occupational scientists in Africa need to work collaboratively and focus on the alleviation of poverty as a fundamental human need ${ }^{5}$, as well as recognise that the access to rehabilitation is also a human right and an occupational justice issue.

\section{The relevance of EBP for occupational therapy practice}

Put simply, EBP centres on using research findings in collaboration with client values and preferences and therapists' clinical wisdom to inform occupational therapy practice ${ }^{6}$. Evidence-based occupational therapy (EBOT) has grown out of a movement to develop evidence-based medicine (EBM). The term EBM was coined in the early 1990s by epidemiologists at McMaster University in Canada ${ }^{7}$. With the wider adoption of EBM by other health professions, the terms EBP and evidence-based health care evolved ${ }^{8}$. The earliest, and probably the most quoted, definition states that EBM was "the conscientious, explicit and judicious use of current best evidence in making decisions about the care of individual patients/clients"9:71. Further development of the concepts of EBM and EBP led to the recognition of the importance of including patient's values and the therapist's clinical reasoning in this process. These ideas were incorporated into a definition by Dawes et al $^{10}$ which stated that "evidence-based practice (EBP) requires that decisions about health care are based on the best available, current, valid and relevant evidence. These decisions should be made by those receiving care, informed by the tacit and explicit knowledge of those providing care, within the context of available resources".

Within rehabilitation, Hoffmann, Bennett and Del Mar " conceptualised EBP as the process of combining information about patients' values and circumstances together with research evidence, the therapists' professional knowledge and experience, and information about the practice context to enable decision-making. They further postulated that the integration of information from the four elements of EBP occurs during the clinical reasoning process. Recent development in EBP has extended these definitions further to recognise the fundamental role of the environment and stakeholders in the development and use of evidence ${ }^{12}$. Occupational therapists are committed to providing the most effective and safe interventions for clients. Practitioners seek the confidence that interventions provided are effective and safe in order to attain best outcomes and to build the respect and trust of clients and the public. In addition, funders of services are increasingly using evidence as the basis for deciding how to invest money to benefit the health of the population as a whole ${ }^{13}$.

\section{THE PROCESS OF EBP}

To facilitate the use of evidence in practice, Sackett ${ }^{14}$ advocated the use of the five steps in the EBP process, namely:

I. Convert information needs into answerable questions

2. Find the best evidence to answer the questions

3. Critically appraise the evidence

4. Apply the evidence in practice

5. Evaluate practice.

Each step is elaborated in the sections that follow.
Step I: Ask the right question

The initial step involves defining the practice question to be answered. Questions are derived from scenarios arising from practice. Asking the right question is critical to finding the most applicable evidence. Several types of questions have been described in the literature. For example, a recent occupational therapy text outlined four types: intervention, client experiences and concerns, diagnosis and prognosis ${ }^{11: 27}$. It is immediately evident that the terminology used originates within the medical model and requires a shift towards terms that embrace the holistic nature of occupational therapy practice, for example, a more suitable term for 'diagnosis' would be 'assessment'. While questions may relate to a range of areas of interest to occupational therapists, this paper focuses on questions about intervention.

A well-used strategy to formulate clinical questions for EBP is the Participant, Intervention, Comparison, Outcome (PICO) format ${ }^{15}$. $A$ recent study of the clinical questions posed by rehabilitation therapists revealed that the PICO structure could not capture all the elements therapists included in their questions ${ }^{16}$. While the PICO approach is useful, it does not recognise the role of the environmental context in which interventions are developed and delivered. Schlosser, Koul and Costello ${ }^{12}$ formulated an expanded PICO approach, namely PESICO, which appears to have considerable merit for application to CBR. PESICO stands for Population, Environment, Stake holders, Intervention/management strategy, Comparative intervention and Outcome.

\section{Step 2: Search for the evidence}

The best evidence must be located to answer the question. This requires planning a good search strategy before doing the search. Planning a search will increase the likelihood of finding any published research that will help to answer the question. A search strategy is developed by identifying key concepts and terms, listing synonyms or related terms, combining the search terms with Boolean operators (AND, OR and NOT) and finally, deciding on the databases that are most likely to contain the evidence required ${ }^{17}$.

The most efficient way to answer questions about 'intervention' is to start by searching evidence-based sources. These are specialised databases containing research that has already been appraised by experts that are updated regularly with evidence from qualityassessed research, for example The Cochrane Library and OTseeker. Once the search has been done and relevant articles identified, they need to be screened to select the articles most directly linked to the question. For questions related to intervention, only articles reporting intervention studies should be selected. From these, the studies that specifically match the question should be identified. A hierarchy of evidence is used to select the study design that provides the most robust evidence (that is, the most free from bias). Each question type has a different hierarchy".

\section{STEP 3: Appraise the evidence}

When pre-appraised sources are not available, the literature needs to be appraised due to variations in the quality of published research. Critical appraisal is the process of reviewing, assessing and interpreting evidence by systematically considering its rigour, results and relevance to the context under consideration. Appraisal should cover three main areas: the validity of the results, the results themselves, and how the results inform client care ${ }^{18}$. Critical appraisal forms and guidelines are available on websites such as those of the Occupational Therapy Evidence-based practice Research Group at McMaster University ${ }^{19}$, the Centre for Evidence-based Medicine $^{20}$, and the Critical Skills Appraisal Programme ${ }^{21}$. These sites contain critical appraisal checklists and guidelines and tutorials on quantitative and qualitative methodological issues.

\section{STEP 4: Apply the evidence}

Having read the article, the therapist needs to consider how this knowledge can be used in the practice context. The following questions need to be considered ${ }^{\prime \prime}$ : 
- Do the results apply to the particular practice and clients?

Do the benefits of the intervention outweigh the potential

harms, costs and inconveniences?

What other factors may need to be considered when applying this evidence?

- How much will it cost?

- How many sessions may be involved?

- How far will the client (or occupational therapist) need to travel?

- Are the resources available to provide the intervention?

- Are the necessary skills available for providing the intervention?

\section{STEP 5: Evaluate practice}

Once the intervention has been implemented, the practice needs to be evaluated to determine whether the intervention actually makes a difference and is sustainable. Adjustments or changes may then need to be made. According to Herbert et al, this step entails "reflect[ing] on whether the process was carried out well and produced the best outcomes for the patient"|3:219. The outcomes and the process of practice may be evaluated. Methods that may be used to evaluate the process of practice include audit, peer assessment of performance and reflection on practice. Herbert et $a{ }^{13}$ provide a helpful discussion on each of these methods and propose questions for each step of the EBP process to facilitate reflection on practice.

\section{THE EVIDENCE FOR CBR}

A comprehensive literature search of the following databases was conducted to locate articles where EBP and $C B R$ were investigated - AMED, CINAHL, CDSR, ACP Journal Club, DARE, EMBASE, HealthSTAR, Ovid MEDLINE(R). The search terms used were 'evidence-based practice', 'community based rehabilitation', 'community occupational therapy', 'community physiotherapy', 'community rehabilitation', 'evidence-based rehabilitation', 'best practice' and 'evidence'. After removal of duplicates, 3 I articles were identified. After review of these articles, 23 were eliminated as they applied to specific clinical services (e.g. mental health, stroke) within a North American or European context, not to CBR as practised in Africa.

Appraisal of the remaining literature indicated that the work to link the concepts and practice of EBP to community-based rehabilitation is early in its development. In a review of 128 published CBR research articles, Finkenflugel, Wolffers and Huijsman ${ }^{22}$ found that most CBR research was theoretical or descriptive in nature, with few rigorous evaluative studies and systematic reviews. Their primary recommendation was that more research into the effectiveness of CBR should be conducted as a matter of urgency. Kuipers and Hartley ${ }^{23}$ developed a methodological framework for the appraisal of CBR evidence. The framework built important CBR principles into a standard critical appraisal process which was primarily applicable to qualitative research studies. Principles included in the appraisal process were collaboration with key stakeholders, accessible outcomes, a rich description of programme methods to assist in replication, and easy-to-understand language for reporting the results and their implications for policy.

Two articles highlighted the need to use evidence and evaluate outcomes in community programmes to ensure consistency across programmes and communities ${ }^{24,25}$. The most recent systematic review of evaluations of $\mathrm{CBR}^{26}$ concluded that evidence is fragmented or insufficient with regard to the effectiveness, efficacy and costs of CBR. This may be due to reports and evaluations being produced as technical reports, usually for donors and NGOs who are the main service providers, rather than as published papers. This gap could however, be easily filled through research collaboration between occupational therapy academics and practitioners working in the public and private sectors and NGOs. Grey literature from donor organisations, DPOs and NGOs should be systematically reviewed to provide more accurate evidence on the effectiveness and efficiency of CBR programmes.

\section{Building evidence for CBR}

To work towards the realisation of equal opportunities for disabled people, a concerted effort, both to generate evidence on how the articles in the UNCRPD and the components in the CBR guidelines are being achieved, and to ensure that rehabilitation programmes are strongly grounded in research knowledge, is essential. Evidence can be generated from routine practice that is well documented and enables the collection of quality data ${ }^{27}$. In psychotherapy, this process of generating evidence from routine practice has been termed 'practice-based evidence ${ }^{27}$. The principles of inclusion, participation, sustainability, empowerment and self-advocacy that guide CBR practice may be used to guide the collection of information related to the indicators and outcomes which are necessary as evidence.

In the $\mathrm{WHO}$ review of CBR in 2003, poverty reduction was included as a goal and a matrix ${ }^{28}$ and was developed to reflect the comprehensive approach of CBR (see Figure I on page 59). The matrix consists of five components of CBR each having five elements which describe the activities and programmes that can be developed for each component ${ }^{28}$. The CBR guidelines ${ }^{3}$ indicate goals and desirable outcomes for each element. The matrix therefore provides a framework that could be used to map occupational therapy CBR research and identify gaps in the evidence.

The matrix demonstrates where the activities and programmes under the 'health' component link to the activities and programmes under any of the other components. 'Empowerment' is viewed as cutting across the other four components. For example, the provision of assistive devices under the health component will not only assist children with disabilities to participate in school, it will also facilitate participation in sport, leisure, family relationships and cultural and religious activities, which are part of the social component.

The UNCRPD and CBR guidelines emphasise the integral and critical role that DPOs and disabled people and their families play in the conceptualisation and implementation of all aspects of CBR programmes $^{2,3}$. In the context of EBP, disabled people and their families or caregivers should play a major role in advocating for, and insisting that, rehabilitation programmes are strongly grounded in knowledge generated through research. As the research evaluating CBR increases, it is vital that occupational therapists use this knowledge to strengthen their practice. If CBR programmes are evidence-based, government may be persuaded to commit additional resources so that the goal of achieving equal opportunities for disabled people may be realised.

\section{APPLYING EBP CONCEPTS TO CBR}

In this section, the application of the steps of EBP to CBR as practiced by occupational therapists is illustrated using a South African example. The example describes how steps I to 4 of the 5 step process may be applied.

\section{Scenario}

Questions emerge from practice scenarios such as the one outlined below:

An occupational therapist involved in a CBR programme run by a local NGO, is working with a group of adults with physical disabilities who live in an informal settlement. The group consists of men and women aged between 25 and 40 years who have been disabled and unemployed for more than five years. The therapist decides to investigate the most effective methods for enabling them to access employment.

\section{Step I: Asking the right question}

The question to be answered is directed at intervention. The key PESICO $^{12}$ components are shown in Table I on page 59.

The question may be phrased as follows: What return to work strategies are most effective in enabling unemployed adults living with a physical disability in an informal settlement to access employment opportunities? 


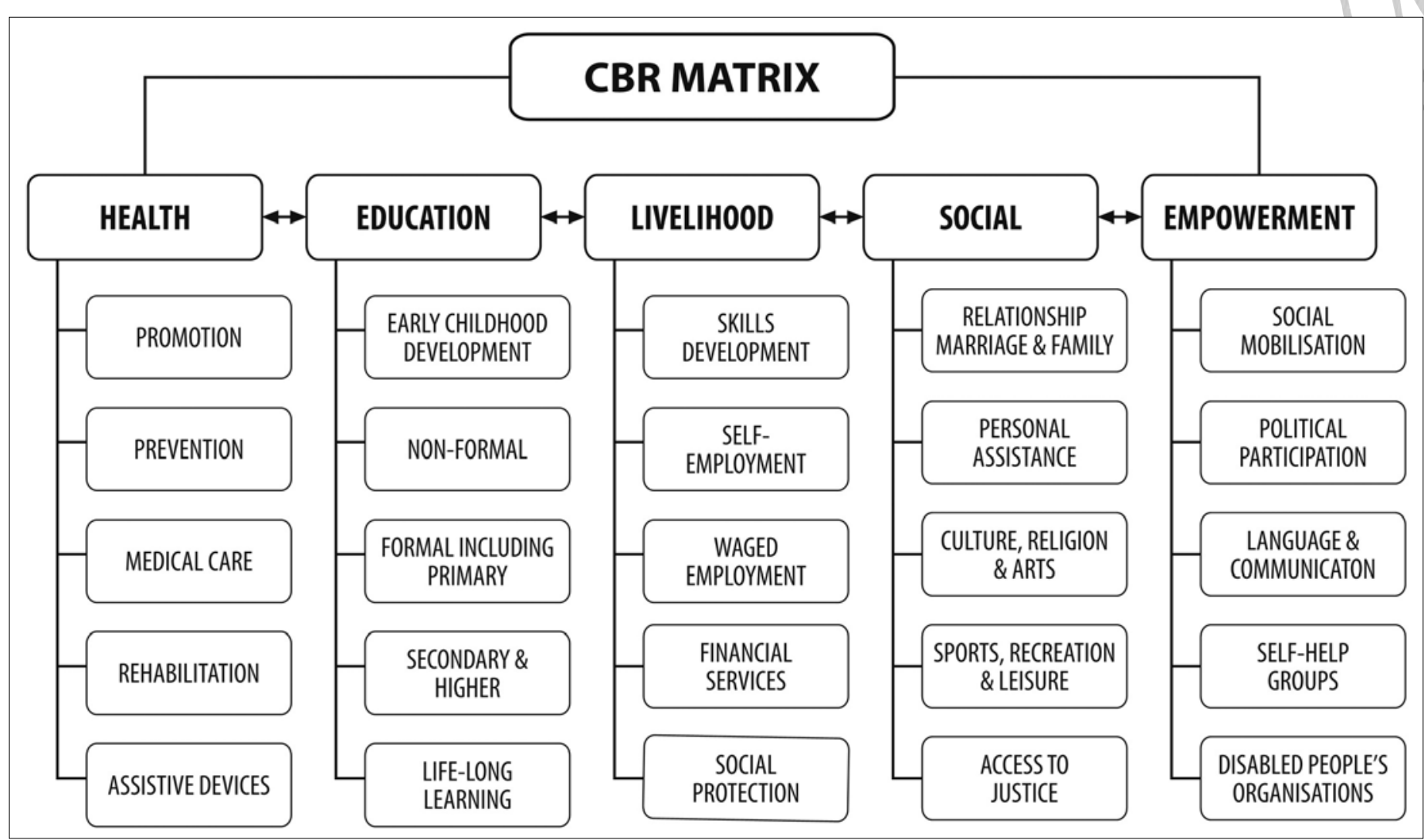

Figure I: CBR matrix (WHO, 20I0)

Table I: PESICO elements for example I

\begin{tabular}{|l|l|}
\hline Population & Adults of employable age with physical disabilities \\
\hline Environment & Unemployed and living in an informal settlement \\
\hline Stake holders & $\begin{array}{l}\text { Family members, disabled peoples organisations, } \\
\text { service providers }\end{array}$ \\
\hline Intervention & Strategies to enable return to work \\
\hline Comparison & No intervention \\
\hline Outcome & Successful employment \\
\hline
\end{tabular}

Step 2: Acquiring the evidence

The PESICO question helps in constructing the search strategy. The key words and possible synonyms or related terms that could be used in the search are shown in Table II.

The key words were combined as follows:

(work OR employ* OR job OR occupation) AND disab* AND (opportunit* OR program* OR intervention* OR strategy* OR promot* or reintegr* OR integrat* OR re-entry) AND (CBR OR community-based rehabilitation).

There are several databases that may contain the evidence required. These can be searched simultaneously using EBSCOHost. In EBSCOHost, the following databases were selected: Academic search premier, Business Source Premier, Africa-Wide Information, CINAHL, EconLit, ERIC, Health Source: Nursing/ Academic Edition, Humanities International Complete; MEDLINE, SocINDEX. Limits set included: peer-reviewed journals, publication dates: 2003-20 I3. Each term was searched individually and then related sets were linked. Finally all the sets were linked and 175 articles were identified. By selecting 'adults' as a limit, 32 articles were located of which three were relevant (refer to Table III).

\footnotetext{
I An asterisk (*) is used when words may have several different forms.

${ }^{2}$ Brackets must be used around words linked with OR.
}

Table II: Key words, synonyms and related terms for the search

\begin{tabular}{|l|l|}
\hline Key word & Synonym / related term \\
\hline Work & Employment \\
\hline \multirow{4}{*}{ Disability } & Job \\
\cline { 2 - 2 } & Occupation \\
\hline Strategy & Impairment \\
\hline \multirow{5}{*}{} & Opportunity \\
\cline { 2 - 2 } & Programme \\
\cline { 2 - 2 } & Intervention \\
\cline { 2 - 2 } & Promotion \\
\cline { 2 - 2 } & Reintegration \\
\cline { 2 - 2 } & Integration \\
\cline { 2 - 2 } & Re-entry \\
\hline Community-based rehabilitation & CBR \\
\hline
\end{tabular}

\section{Table III: Relevant articles identified}

Niemeier J, DeGrace S, Farrar L, Ketchum J, Berman A, Young J. Effectiveness of a comprehensive, manualized intervention for improving productivity and employability following brain injury. Journal of Vocational Rehabilitation, 2010; 33: I67-I 79.

Shankar J. Improving job tenure for people with psychiatric disabilities through ongoing employment support. Australian e-Journal for the Advancement of Mental Health, 2005; 4(I): I-II .

Citron T, Brooks-Lane N, Crandell D, Bradya K, Cooper M, Revell $\mathrm{G}$. A revolution in the employment process of individuals with disabilities: Customized employment as the catalyst for system change. Journal of Vocational Rehabilitation, 2008; 28: 169-179. 
The article by Shankar ${ }^{29}$ investigated factors that enabled people with psychiatric disabilities to stay employed while Citron et a ${ }^{30}$ reported the outcomes of a systems change approach to customising employment opportunities to persons with mental illness, developmental disabilities, and addictive diseases. Neither of these articles was appropriate for answering the PESICO question as they related to psychosocial disabilities. The third article reported the "findings of a prospective, repeated measures design and controlled trial of a 20-session, manualised, employability-enhancing intervention for community-dwelling persons with acquired brain injury attending six work-centered clubhouses"31:167. Although the study involved people with acquired brain injury, the findings may be useful for adults with other physical disabilities.

\section{Step 3: Appraise the evidence}

The quantitative critical appraisal form ${ }^{32}$ and guidelines ${ }^{33}$ developed by the Occupational Therapy Evidence-based practice Research Group at McMaster University are helpful tools for guiding the appraising process. For the purposes of this article, only the key strengths and limitations of the chosen article ${ }^{31}$ are highlighted.

Firstly, the study used a controlled trial design so allocation of participants to the intervention or control group was not randomised. This may have introduced bias which could have influenced the outcomes of the intervention. To determine whether this was an issue in the study, the baseline characteristics of the participants in the two groups were examined to ascertain whether there were any differences between them. Table $\|\left.\right|^{31: 170}$ shows some differences but statistical analysis revealed that these were not significant with respect to age, gender, ethnicity, education, disability status, working pre-injury or pre-intervention, and productivity pre-intervention. Therefore, any changes shown at the end of the study may be attributed to the effects of the intervention.

The outcome measures that were used at baseline and after the intervention seem appropriate and some aspects of validity and reliability were tested so there is some assurance that the instruments measured what they said they measured. The staff members involved were trained to use the outcome measures and measurements were done independently at the start and at three points during the study. A consistent staff member completed the ratings at five of the six clubhouses which enhanced the reliability of the measurements. The intervention topics and purpose were described in the text and in more detail in a figure, thus it is possible to replicate the intervention provided further information on the exact nature of the intervention could be obtained from the authors.

Potential participants were involved in the design of the intervention. There is a possibility that contamination occurred as there was at least one treatment and control group at each clubhouse. As a result, the control group may have found out what was covered in the intervention group. This would however, have reduced the effects of the intervention which showed a significant increase in the productivity of participants in the intervention group. There was no difference in the percentage of participants who were working after the intervention in the intervention and control groups. The probability of employment was significantly affected in participants who received a disability income, with those who did not receive an income being significantly more likely to be employed. The authors concluded that there were "Modestly significant treatment effects for employment status and productivity' and that 'The program appears to have a positive effect on job stability"31: 167.

\section{Step 4: Apply the evidence}

Reflection on whether the results could be applied within the scenario raised several issues. Firstly, the study was conducted in five brain injury clubhouses in a State in America and therefore the findings are not generalisable to the setting (informal settlement in a community in South Africa) or the population (adults between 25 and 40 years old with physical disabilities) in our scenario. The clubhouse model, however, shares some principles with CBR, namely it is based in the community, aims to fully integrate people with disabilities into society, uses an empowerment approach and has limited resources and funding.

Secondly, is the intervention appropriate and can it be implemented in such a different context? In terms of the costs, these would be low as the intervention requires only time from the occupational therapist, materials required are minimal and a venue in the community could be used for the sessions. The intervention as described in the study consisted of 20 sessions (two per week over 10 weeks) each with a 5-part format. Topics were outlined and sessions consisted of participatory task-based discussions, individual reflection, role plays, demonstrations, brain storming and problem-solving. As the intervention could be offered within the community from which the people lived, travelling time and costs would not be a barrier to accessing services for the participants or the occupational therapists (who worked in the community). Minimal resources are required for the intervention. The skills required to provide the intervention fall within the skills set of an occupational therapist, therefore additional training is not required. If necessary, guest speakers could be invited to assist with some topics. In terms of the relevance of the topics, some may not apply to the population in our scenario, but these could be replaced with others that are more applicable to the South African context and this group in particular. Although the population and environment in our scenario differs from that of the study, the potential harms, costs and inconveniences are minimal and thus, the benefits of the intervention appear to be worthwhile. While the study results ${ }^{31}$ cannot be generalised to the population in our scenario, trends can be noted and applied. In addition, considering the absence of stronger evidence, the modest benefits could be worthwhile pursuing. Due to the high rate of unemployment in South Africa, any intervention that contributes may be better than doing nothing provided the risks are minimal.

\section{STEP 5: Evaluating practice}

The CBR Guidelines and the UNCRPD regard identifying outcomes for monitoring and evaluation before a CBR programme is implemented as essential for advocating for more resources from government, and providing practice that is relevant ${ }^{2,3}$. Structures and systems for monitoring disability inclusion in activities and services, and ensuring that information and documentation are accessible, are essential to an organisation's capacity to act on and in the world in order to effect social change. In designing inclusive services and programmes, both qualitative and quantitative indicators need to be developed to monitor changes in access and participation. These indicators should be aligned to a specific programme that corresponds to the elements of one or more of the five components of CBR that the organisation has chosen as its focus. The challenge is to determine the indicators that can measure these occupational outcomes.

\section{DISCUSSION}

The growing need and opportunity for occupational therapists to engage in policy processes in the different fields of practice is essential as occupational therapy can contribute significantly to the health, well-being and quality of life of individuals, families and communities. The continued inequality in education and employment, especially for youth who comprise more than $50 \%$ of the population, is an area where the occupational therapy profession should focus more attention ${ }^{34}$. In this regard, the CBR Guidelines provide a framework for monitoring occupational therapy practice in the public, NGO and private sectors, as they provide clear descriptions of each element of the five components - Health, Education, Livelihood, Social and Empowerment. A further advantage is that the five components in the CBR guidelines are responsive to the articles of the UNCRPD. By collecting data that can be analysed and compared across provinces, the occupational therapy profession will be able to respond to policy imperatives by providing evidence of the successes and remaining gaps in policy implementation. Such monitoring of implementation strategies is intended to improve 
the lives of children through education, youth and adults through different forms of decent work, and the elderly by providing a network of social support systems. The profession has the expertise to monitor outcomes across health, education, labour, and social networks including family life and community living. Having sound policies that are implemented and monitored appropriately will improve service delivery and lead to better health, education and employment outcomes which will ultimately strengthen the development and implementation of CBR within the Re-engineering of Primary Health Care.

The CBR guidelines provide a broad variety of potential process and outcome measures, as well as indicators, that enable the collection of baseline data - both quantitative and qualitative. To ensure that all key outcomes can be monitored and reported effectively, outcome measures and indicators must be selected before programmes are implemented. Careful planning of data collection is thus essential to enable monitoring of change over time. In this regard, academic institutions have a critical role to play through equipping undergraduate and postgraduate students with the knowledge and skills to implement the principles of EBP in the different contexts in which they work. The new CBR Guidelines with the matrix (see Figure I) provide a useful framework for monitoring and evaluation as each element under the five components has been clearly defined. In this regard, they provide a common language across different contexts. The guidelines make it possible to monitor rehabilitation processes and outcomes across the continuum of health care as hospital interventions are included under the medical care and rehabilitation elements of the Health component. Reporting of continuous reflection-on-and-in-action is an integral process in CBR as a community development strategy, which has the added advantage of providing data for triangulation with other data sources. The gap in available evidence for CBR could be addressed by developing communities of practice with key stake holders who work collaboratively to identify the evidence needed for CBR and plan and implement the process required to obtain it. The fruit of such collaboration would be a framework for policy implementation and monitoring of rehabilitation services and disability-inclusive development programmes that have the consensus of all providers as well as persons with disabilities and their families.

\section{CONCLUSION}

This paper has demonstrated how EBP may be applied in contexts when a CBR approach is taken to service delivery. The worked example demonstrates how therapists can apply each step of the EBP process within CBR programmes. More examples of how the concepts of EBP may be applied within CBR are needed to guide therapists in its implementation. It is argued that EBP has to go handin-hand with practice-based evidence so that the evidence that is needed for CBR is generated. This requires occupational therapists to be adequately equipped to implement EBP and to document their practice appropriately and accurately so that the evidence required for CBR may be generated (practice-based evidence). Having this kind of evidence will enable the profession to lobby for the resources needed to implement CBR programmes thus realising the goals of primary health care. To this end, partnerships between academics and practitioners should be strengthened through forming communities of practice. Lastly, undergraduate and postgraduate education and continuing professional development programmes should incorporate elements of EBP and practice-based evidence so that students and therapists learn to apply evidence within CBR while simultaneously creating the evidence needed to support it.

\section{REFERENCES}

I. Bannigan K. A global approach to evidence based occupational therapy: what progress has been made since 2006? WFOT Bulletin. 20II; 64: 4-6.

2. United Nations. Convention on the rights of persons with disabilities. United Nations, 2006.
3. World Health Organization. Community-based rehabilitation: $C B R$ guidelines. Geneva: World Heath Organization, 2010.

4. United Nations. World Programme of Action concerning disabled persons. New York United Nations General Assembly, 1982.

5. Max-Neef M. Human scale development: conception, application and further reflections. New York: The Apex Press, I99I.

6. Law M. Evidence-based rehabilitation: A guide to practice. Thorofare, NJ.: Slack Incorporated, 2002.

7. Dickersin K, Straus $\mathrm{S}$ and Bero L. Evidence based medicine: increasing, not dictating, choice. British Medical Journal. 2007; 334: 10.

8. Bennett $S$, Townsend E, Mancini M and Taylor $C$. Evidence-based practice in occupational therapy: international initiatives. WFOT Bulletin. 2006; 53: 6-12.

9. Sackett D, Rosenberg W, Gray J, Haynes R and Richardson W. Evidence-based medicine: what it is and what it isn't. British Medical lournal. 1996; 312: 7I-2.

10. Dawes M, Summerskill W, Glasziou P, Cartabellotta A, Martin J, Hopayian K, Porzsolt F, Burls A and Osborne J. Sicily statement on evidence-based practice. BMC Medical Education, 2005; 5 : doi: I0.I I86/I472-6920-5-I. http://www.biomedcentral.com/I472$6920 / 5 / 1$

II. Hoffmann T, Bennett S and Del Mar C. Evidence-based practice across the health professions. Sydney: Elsevier, 2013.

12. Schlosser R and O'Neil-Pirozzi T. Problem-formulation in evidencebased practice and systematic reviews. Contemporary Issues in Communication Science \& Disorders. 2006; 33: 5- 10.

13. Herbert R, Jamtvedt G, Mead J and Hagen K. Practical evidencebased physiotherapy. Edinburgh: Elsevier, 2005.

14. Sackett D. Evidence-based medicine. Seminars in Perinatology, 1997; 2I: 3-5.

15. Sackett D, Strauss $S$ and Richardson W. Evidence-based medicine: how to practice and teach EBM. Edinburgh: Churchill Livingstone, 2000.

16. Kloda $L$ and Bartlett J. A characterization of clinical questions asked by rehabilitation therapists. Journal of the Medical Library Association, 2014; 102: 69-77.

17. Law M and MacDermid J. Evidence-based Rehabilitation: a guide to practice. Thorofare, NJ: Slack Inc, 2013.

18. Critical Skills Appraisal Programme. "Appraising the evidence." 2013. < http://www.casp-uk.net/\#!criticalappraisal/cltsl > (04 March 20I5).

19. Occupational Therapy Evidence-based Practice Research Group. 2008. <http://www.srs-mcmaster.ca/ResearchResourcesnbsp/ ResearchGroups/CentreforEvidenceBasedRehabilitation/EvidenceBasedPracticeResearchGroup/tabid/630/Default.aspx > (4 March 2015).

20. Centre for Evidence-based Medicine. "Critical appraisal tools." 2014. <http://www.cebm.net/critical-appraisal/> (4 March 2015)

21. Critical Skills Appraisal Programme. "CASP checklists." 2013. $<$ http://www.casp-uk.net/\#!casp-tools-checklists/cl8f8 > (04 March 20I5).

22. Finkenflugel $H$, Wolffers I and Huijsman $R$. The evidence base for community-based rehabilitation: a literature review. International Journal of Rehabilitation Research, 2005; 28: 187-20I.

23. Kuipers $P$ and Hartley S. A process for the systematic review of community-based rehabilitation evaluation reports: formulating evidence for policy and practice. International Journal of Rehabilitation Research, 2006; 29: 27-30.

24. Ryan-Woolley B, Wilson K and Caress A. The implementation and evaluation of a community rehabilitation team: a case study. Disability and Rehabilitation, 2004; 26: 817-26.

25. Vander Laan R, Brandys C, Sullivan I and Lemsky C. Integration through a city-wide brain injury network and best practices project. NeuroRehabilitation, 2001; 16: 17-26.

26. Grandisson M, Hébert $M$ and Thibeault R. A systematic review on how to conduct evaluations in community-based rehabilitation. Disability and Rehabilitation, 20I4; 36: 265-75.

27. Margison F, McGrath G, Barkham M, Clark J, Audin K, Connell J and Evans C. Measurement and psychotherapy: Evidence-based practice and practice-based evidence. The British Journal of Psychiatry, 2000; 177: $123-30$

28. World Health Organization. "About the community-based rehabilitation (CBR) matrix." 2015. < http://who.int/disabilities/cbr/matrix/ 
en/> (4 March 2015).

29. Shankar J. Improving job tenure for people with psychiatric disabilities through ongoing employment support. Australian e-Journal for the Advancement of Mental Health, 2005; 4: I-II.

30. Citron T, Brooks-Lane N, Crandell D, Bradya K, Cooper M and Revell G. A revolution in the employment process of individuals with disabilities: Customized employment as the catalyst for system change. Journal of Vocational Rehabilitation, 2008; 28: 169-79.

31. Niemeier J, DeGrace S, Farrar L, Ketchum J, Berman A and Young J. Effectiveness of a comprehensive, manualized intervention for improving productivity and employability following brain injury. lournal of Vocational Rehabilitation, 2010; 33: 167-79.

32. Law M, Stewart D, Pollock N, Letts L, Bosch J and Westmorland M. "Critical review form - Quantitative studies." 1998. <http:// www.srs-mcmaster.ca/Portals/20/pdf/ebp/quanreview.pdf $>$ (25 September 2014).

33. Law M, Stewart D, Pollock N, Letts L, Bosch J and Westmorland M. "Guidelines for critical review form - Quantitative studies." 2008. $<$ http://www.srs.mcmaster.ca/Portals/20/pdf/ebp/quanguidelines. pdf $>$ (25 September 20l4)

34. Lorenzo T, Motau J, van der Merwe T, Janse van Rensburg J and Cramm JM. Community rehabilitation workers as catalysts for disability: inclusive youth development through service learning. Development in Practice, 2014; I: I-9.

\section{Corresponding Author}

\section{Helen Buchanan}

Division of Occupational Therapy,

Department of Health and Rehabilitation Sciences,

University of Cape Town

F45 Old Groote Schuur Hospital Building,

Observatory, 7925,

South Africa

helen.buchanan@uct.ac.za 